\title{
Jefferson
}

Thomas Jefferson University

The Medicine Forum

2016

\section{A Difficult Conversation}

Shuwei Wang, MD

Thomas Jefferson University, shuwei.wang@jefferson.edu

Follow this and additional works at: https://jdc.jefferson.edu/tmf

Part of the Internal Medicine Commons

Let us know how access to this document benefits you

\section{Recommended Citation}

Wang, MD, Shuwei (2016) "A Difficult Conversation," The Medicine Forum: Vol. 17, Article 23.

DOI: https://doi.org/10.29046/TMF.017.1.023

Available at: https://jdc.jefferson.edu/tmf/vol17/iss1/23

This Article is brought to you for free and open access by the Jefferson Digital Commons. The Jefferson Digital Commons is a service of Thomas Jefferson University's Center for Teaching and Learning (CTL). The Commons is a showcase for Jefferson books and journals, peer-reviewed scholarly publications, unique historical collections from the University archives, and teaching tools. The Jefferson Digital Commons allows researchers and interested readers anywhere in the world to learn about and keep up to date with Jefferson scholarship. This article has been accepted for inclusion in The Medicine Forum by an authorized administrator of the Jefferson Digital Commons. For more information, please contact: JeffersonDigitalCommons@jefferson.edu. 


\section{A Difficult Conversation}

Shuwei Wang, MD

I put on my isolation gown, knocked on his hospital room door, and entered to initiate the family meeting. I had been dreading this meeting all morning. It is never easy telling the loved ones of a thirty-seven year old that his disease is terminal, and he is actively dying.

I greeted Mr. M, his girlfriend and sister with the help of a Spanish translator. He smiled and had a twinkle in his jaundiced eyes. He was debilitated, bed bound with anasarca, his right thigh tightly bound by multiple blood stained pressure dressings. "Hola", I greeted them with the little Spanish I knew. Mr. M had end stage liver disease, causing uncontrolled coagulopathy that led to the bleeding from his right thigh hematoma. His family had a limited understanding of his condition. They were not fully aware that he was actively dying.

I introduced them to the concept of hospice, a facility where treatment goals are shifted towards symptom directed care encompassing the social, spiritual, and psychological needs at the end of life. The translator helped me talk to the family about goals of care, end of life, and code status. Between tears and multiple rounds of Spanish translation, the family asked "Is there any chance he might get better?" I realized that even after a lengthy conversation, families may not be prepared for what was to come. I revisited the severity of his illness, and used the word "dying", to emphasize the seriousness of his condition and create clarity for the family. During the entire conversation, Mr. M followed blankly and nodded in agreement. Between the translator and family members, it was difficult for me to assess how much he really understood. I left unsure how much he or his family understood.

Initiating end of life discussions is never easy, no matter how long we have prepared for it. It is especially hard when a patient in their prime years of life. Learning more about Mr. M, I discovered he was an undocumented worker from Ecuador where most of his family and daughter resided. It was uneasy for me, as his physician, to initiate a conversation about end of life with such a young man. It was unnatural, as our instinct is always to save and preserve life.

The clock turned three. Transport came to pick up Mr. M for hospice. The normally stoic Mr. M shed a few tears. He was extremely gracious to the medicine team and was emotional for the first time. He knew his time was coming, but he also knew he was going somewhere where he would be more comfortable. I untied my yellow isolation gown and in a moment of clarity, a sense of relief came over me as I realized Mr. M would no longer suffer, and sometimes, as physicians, our job is not only to preserve life, but to preserve quality of life. 
The Medicine Forum, Vol. 17 [2016], Art. 23

https://jdc.jefferson.edu/tmf/vol17/iss1/23

DOI: https://doi.org/10.29046/TMF.017.1.023 
Wang, MD: A Difficult Conversation

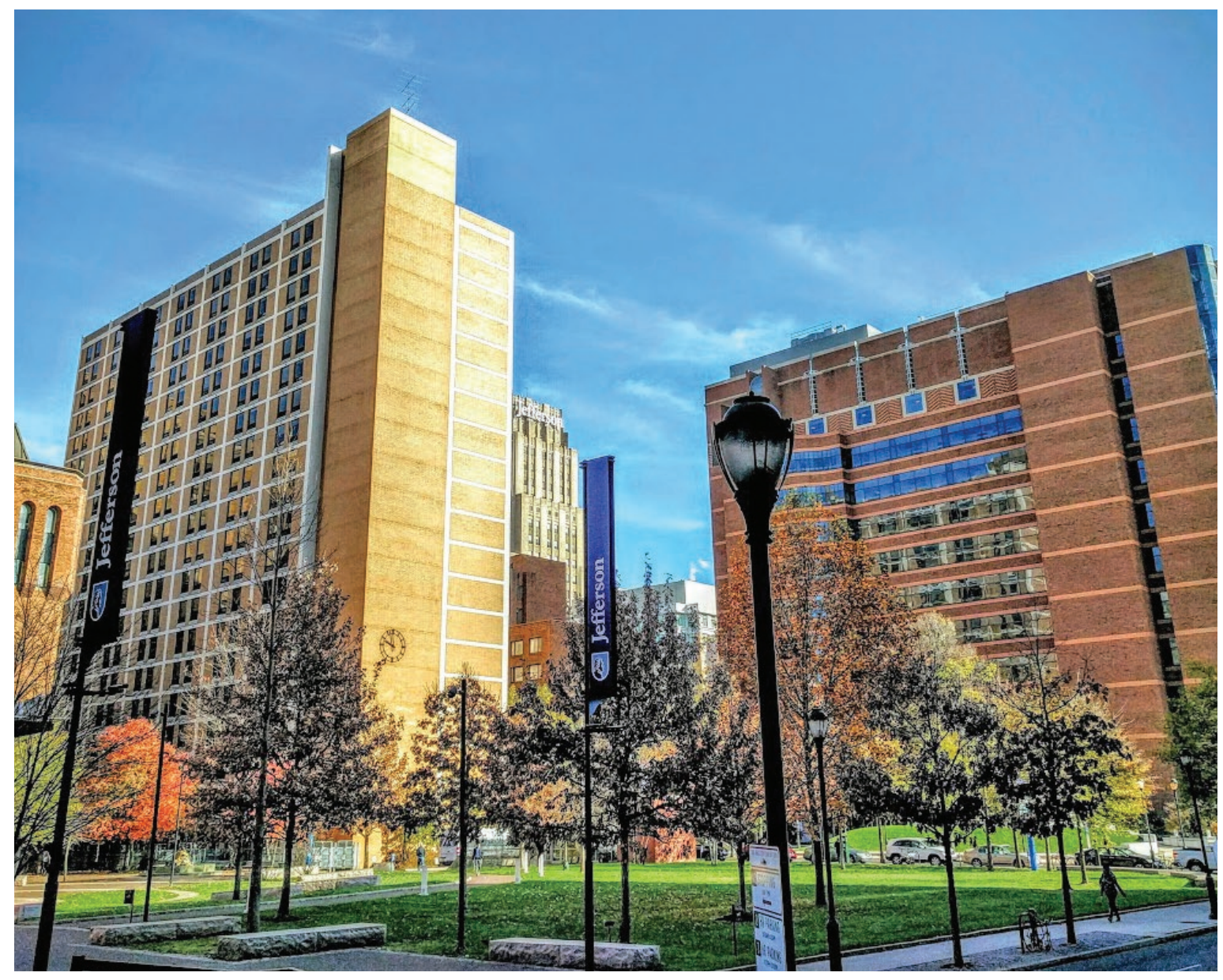

Walter Kraft, MD 